\title{
Erdheim-Chester disease with epiphyseal and systemic disease
}

N A Athanasou, C Barbatis

\begin{abstract}
A case of Erdheim-Chester disease which affected the epiphysis and showed evidence of systemic disease is presented. Clinical and histopathological similarities with other forms of disseminated Langerhans' cell histiocytosis are noted, particularly reaction of infiltrating histiocytes for S100 and HLA-DR.
\end{abstract}

(F Clin Pathol 1993;46:481-482)

Erdheim-Chester disease is a rare histiocytic disorder of adults characterised by an infiltrate of lipid laden foam cells in the bone marrow and a generalised sclerosis of the long bones that usually spares the epiphysis. ${ }^{12}$ Although systemic disease has been reported, this condition is usually separated from disseminated forms of histiocytosis $\mathrm{X}$ or Langerhans' cell histiocytosis on the basis of age and the clinical and radiological patterns of bone and systemic disease, as well as the fact that Langerhans' cells have not been positively identified in the lesion. ${ }^{23}$

\section{Case history}

A 72 year old Greek farmer was admitted

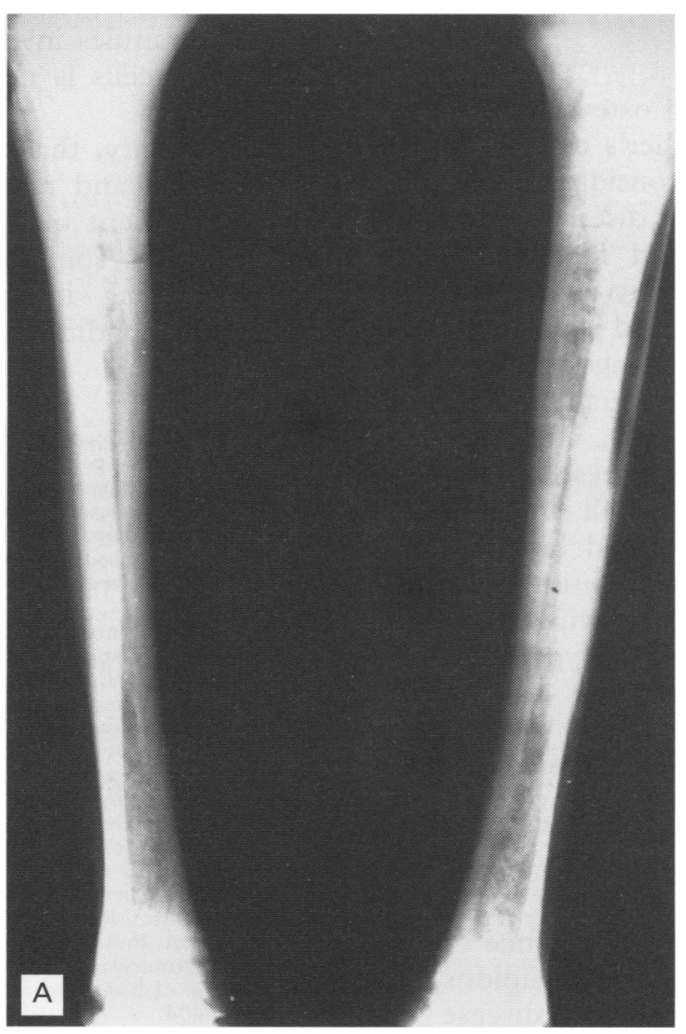

with a two month history of fever $\left(38 \cdot 5-39^{\circ} \mathrm{C}\right)$, generalised arthralgia predominantly affecting the large joints of legs and arms, and severe pain on pressure over the tibial shaft. Eighteen months earlier, he had sustained weight loss and polydipsia and polyuria. Diabetes insipidus was diagnosed in a German clinic and he was treated with pitressin. A lung biopsy specimen taken at that time showed interstitial fibrosis. $\mathrm{He}$ also had a two year history of angina due to ischaemic heart disease. On admission, apart from tenderness over bony tibiae, clinical examination was unremarkable. Investigations showed a haemoglobin concentration of $13.2 \mathrm{~g} / 1$, platelet count of $486 \times 10^{9} / 1$, a white cell count of $9.6 \times 10^{9} / 1$, an ESR of 101 $\mathrm{mm} /$ first hour; blood urea, electrolytes, blood lipids, liver function tests and plasma proteins (including protein electrophoresis) were all normal. Serological tests for syphilis, antinuclear and rheumatoid factors were negative. A chest $x$ ray picture showed diffuse interstitial shadows in both lungs. $x$ Ray pictures of the tibiae and femora showed a generalised mottled sclerotic coarsening of the medullary bone (fig 1A). A bone scan showed increased uptake in these and both forearm bones (fig 1B). A computed tomogram of the skull showed no abnormality.

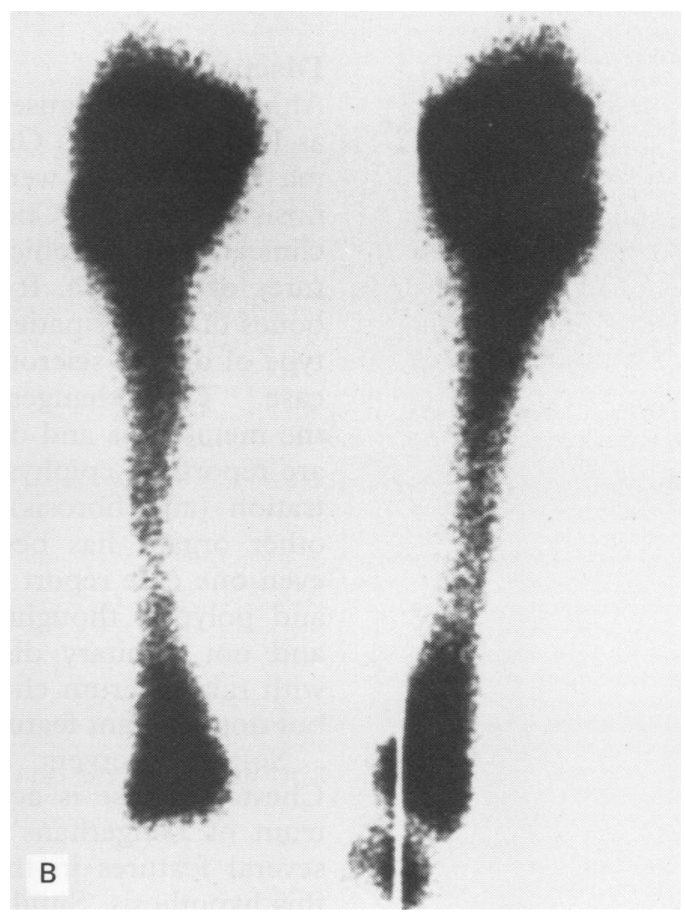

Figure 1 (A) X ray and (B) bone scan of both tibiae showing diffuse osteosclerosis and increased uptake of isotope throughout the entire length of both bones. 


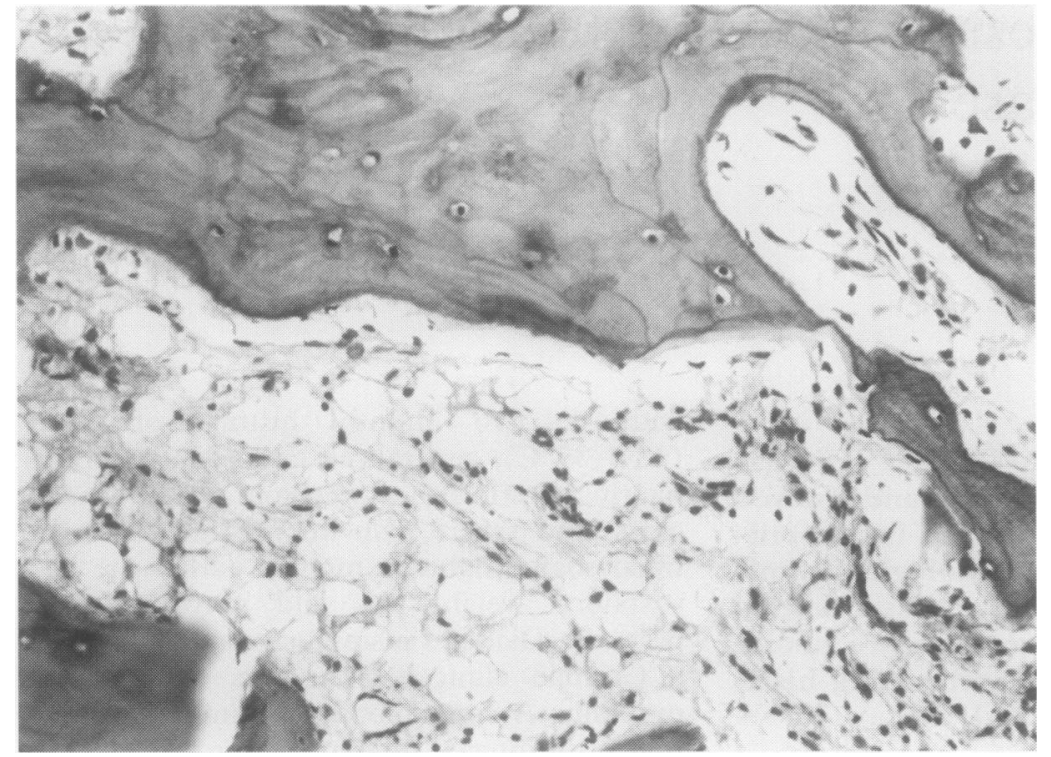

Figure 2 Marrow infiltrate of numerous foamy histocytes and scattered chronic inflammatory cells between woven bone trabeculae containing prominent cement lines (haematoxylin and eosin). called lipoid granulomatosis by Jaffe, ${ }^{3}$ who like others ${ }^{2}$ regarded this condition as distinct from disseminated forms of Langerhans' cell histiocytosis, in particular Hand-SchüllerChristian disease. The latter mostly affects children and is rare in the elderly; it produces infiltrates in the lungs and other organs, commonly affects the pituitary gland, and produces well defined osteolytic lesions in bone. ${ }^{2}$ Exceptions to the typical clinical and radiological pattern of tissue disease by Hand-Schüller-Christian disease are well recognised, and Erdheim-Chester disease itself shows some heterogeneity of bone and systemic pathology. In the late phase of Hand-Schüller-Christian disease foamy histiocytes and fibrosis are the main features $^{23}$; these pathological features are also seen in Erdheim-Chester disease. Immunohistochemical staining of cases of classic Erdheim-Chester disease with antibodies directed against $S 100$ protein, which is known to be present on Langerhans' cells, ${ }^{5}$ has not identified S100 on infiltrating histiocytes before ${ }^{67} \mathrm{It}$ has been noted on a case of bilateral, symmetrical eosinophilic granulomas of both tibiae, however, which showed some similarities with Erdheim-Chester disease. ${ }^{8}$ In the present case, infiltrating histiocytic cells stained strongly for $\mathrm{S} 100$, as well as HLA-DR and CD68, antigens known to be present on cells in eosinophilic granuloma. ${ }^{9}$ In addition to these immunophenotypic similarities, the previously noted clinical, radiological, and histopathological overlap with localised and disseminated forms of Langerhans' cell histiocytosis, and its predominance in the elderly, suggest that Erdheim-Chester disease may represent one of a spectrum of changes occurring in old lesions of disseminated Langerhans' cell histiocytosis. Ultrastructural identification of Birbeck granules in Erdheim-Chester disease infiltrating cells is necessary to confirm this possibility.

In summary, this case highlights the variable clinical and radiological features which may be present in Erdheim-Chester disease and provides some immunophenotypic evidence arguing in favour of its inclusion among the conditions of Langerhans' cell histiocytosis.

1 Resnick D, Greenway G, Genant H, et al. Erdheim Chester disease. Radiology 1982;142:289-95.

2 Mirra JM. Erdheim Chester disease. In: Bone tumours: clinical, radiologic and pathological correlates. Philadelphia: Lea and Febiger, 1989:1074-8.

3 Jaffe HL. Metabolic, degenerative and inflammatory disorders of bone and joints. Philadelphia: Lea and Febiger, 1972: of bone and
$550-60$.

4 Brower AC, Worsham GF, Dudley AH. Erdheim Chester disease: a distinct lipidosis of part of the spectrum of disease: a distinct lipidosis of part of

5 Histiocyte Society Writing Group. Histiocyte syndromes in children. Lancet 1987; i:208-9.

6 Miller RL, Sheeler LR, Bauer TW, Bukowski RM Erdheim Chester disease: case report and review of the literature. Am $\mathcal{F}$ Med 1986;80:1230-6.

7 Molnar CP, Gottschalk R, Gallagher B. Lipid granulomatosis: Erdheim Chester disease. Clin Nuc Med 1988;13:736-41.

8 Strouse PJ, Burton IE, Shifrin LZ, Shah AR. Case Report 710. Skeletal Radiol 1992;21:64-7.

9 Doussis IA, Puddle B, Athanasou NA. Immunophenotype of multinucleated and mononuclear cells in giant cell lesions of bone and soft tissue. $\mathcal{f}$ Clin Pathol 1992;45 398-404. cell histiocytosis include the presence of lung infiltrates and fibrosis, diabetes insipidus, and bone disease. Erdheim-Chester disease was 